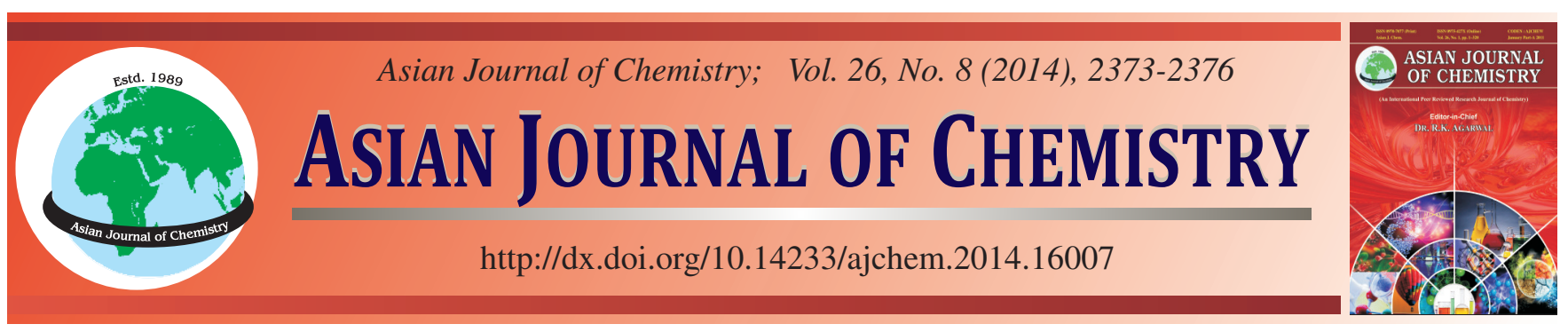

\title{
Preparation of Visible Light Responsive Carbon Doped Titania Catalyst via Simple Sol-Gel Method
}

\author{
J. ZHANG ${ }^{1}$, Y.J. WANG ${ }^{1}$ and S.Z. Hu ${ }^{2, *}$
}

${ }^{1}$ Liaoning Key Laboratory of Petroleum and Chemical Industry, Liaoning Shihua University, Fushun 113001, P.R. China

${ }^{2}$ Institute of Eco-environmental Sciences, Liaoning Shihua University, Fushun 113001, P.R. China

*Corresponding author: Tel: +86 24 23847473; E-mail: hushaozheng001@163.com

Keywords: Carbon doping, $\mathrm{Ti}^{3+}$ species, $\mathrm{TiO}_{2}$, Methylene blue, Photocatalysis.

\section{INTRODUCTION}

Nowadays, semiconductor photocatalytic technique has been given great attention due to its promising applications in purification of air and water pollution by degradation of the organic pollutants ${ }^{1,2}$. Up to now, although various oxide semiconductors have been found possess the photocatalytic ability, $\mathrm{TiO}_{2}$ is still the most important photocatalyst due to its biological and chemical inertness, strong oxidizing power, nontoxicity and long-term stability against photo-corrosion. However, a major barrier to the widespread use of $\mathrm{TiO}_{2}$ as photocatalysts is its relatively large electronic band gap, some 3.0-3.2 eV, limiting its photoresponse to visible light, which comprised of about $43 \%$ of the incoming solar energy. In order to extend the photoresponse of $\mathrm{TiO}_{2}$ into the visible region of the solar spectrum, considerable efforts have been directed towards the doping of $\mathrm{TiO}_{2}$ lattice to modify its electronic band gap and shift its absorption edge to the visible light region. One way to achieve this modification is to dope $\mathrm{TiO}_{2}$ with non-metal, such as nitrogen ${ }^{3}$, sulfur ${ }^{4}$, phosphorous ${ }^{5}$,

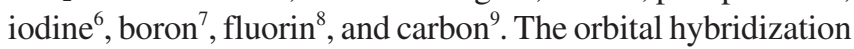
will happen between the atom orbit of the dopant and $\mathrm{O} 2 \mathrm{p}$ orbit of $\mathrm{TiO}_{2}$, which narrow the band gap of $\mathrm{TiO}_{2}$ and shift its absorption edge to the visible light region.

Among those dopant, carbon was considered as the most promising one. Till now, various synthetic routes have been investigated for carbon-doped $\mathrm{TiO}_{2}$ nanoparticles. Wu et al. ${ }^{10}$ prepared carbon doped $\mathrm{TiO}_{2}$ material by gel-hydrothermal method. They suggested that coke carbon generated on the carbon doped $\mathrm{TiO}_{2}$ surface act as a photosensitizer and has the photosensitization effect under the visible light. Park et al. ${ }^{11}$ reported carbon-doped $\mathrm{TiO}_{2}$ was successfully prepared from a conventional sol-gel synthesis without using external carbon precursors. They suggested that the visible light activities of the prepared $\mathrm{TiO}_{2}$ samples for the conversion of 4-chlorophenol and iodide were strongly dependent on the calcination temperature and maximized at around $250^{\circ} \mathrm{C}$. Kang et al. ${ }^{12}$ synthesized a carbon doped titanium oxide powder by mechanochemical (MC) and heating operations. The mechanochemical operation is conducted by grinding $\mathrm{TiO}_{2}$ with ethanol in air and the heating is carried out at different temperatures in air. They considered that the visible light activity was attributed to the presence of $\mathrm{C}-\mathrm{O}$ and Ti-C bond. In this work, carbon doped $\mathrm{TiO}_{2}$ was prepared by an convenient sol-gel method. The photocatalytic performances of prepared samples were evaluated in the degradation of methylene blue under visible light. The possible mechanism was presented.

\section{EXPERIMENTAL}

Carbon-doped $\mathrm{TiO}_{2}$ nanoparticles were synthesized by solgel technique. The analytical grade titanium isopropoxide, ethylene glycol (EG), citric acid (CA), ammonia (25\%) and nitric acid (65-68 \%) were used as raw materials. The detailed process could be described as follows. A certain amount of 
titanium isopropoxide was added to citric acid and ethylene glycol mixture under stirring to arrive molar ratios of CA/Ti, $\mathrm{N} / \mathrm{CA}$ and $\mathrm{CA} / \mathrm{EG}=2: 1,1: 3$ and 1:1. After adjusting the $\mathrm{pH}$ value with ammonia to $6-7$, the mixture solution was evaporated at $80{ }^{\circ} \mathrm{C}$ to gradually form a clear precursor gel. The precursor gel was calcined at the temperature of $300-600{ }^{\circ} \mathrm{C}$ for $2 \mathrm{~h}$ and denoted as CT-300, CT-400, CT-500 and CT-600.

$\mathrm{X}$-ray diffraction (XRD) patterns of the prepared $\mathrm{TiO}_{2}$ samples were recorded on a Rigaku D/max-2400 instrument using $\mathrm{Cu}-\mathrm{K}_{\alpha}$ radiation $(\lambda=1.54 \AA$ ). $\mathrm{UV}$-visible spectroscopy measurement was carried out on a Jasco V-550 spectrophotometer, using $\mathrm{BaSO}_{4}$ as the reference sample. Photoluminescence spectra were measured at room temperature with a fluorospectrophotometer (FP-6300) using an Xe lamp as excitation source. XPS measurements were conducted on a Thermo Escalab 250 XPS system with $\mathrm{Al} \mathrm{K}_{\alpha}$ radiation as the exciting source. The binding energies were calibrated by referencing the $\mathrm{C} 1 \mathrm{~s}$ peak $(284.6 \mathrm{eV})$ to reduce the sample charge effect.

Methylene blue was selected as model compound to evaluate the photocatalytic performance of the prepared $\mathrm{TiO}_{2}$ particles in an aqueous solution under visible light irradiation. $0.1 \mathrm{~g} \mathrm{TiO}_{2}$ powders were dispersed in $100 \mathrm{~mL}$ aqueous solution of methylene blue (50 ppm) in an ultrasound generator for 10 min. The suspension was transferred into a self-designed glass reactor and stirred for $0.5 \mathrm{~h}$ in darkness to achieve the adsorption equilibrium. In the photoreaction under visible light irradiation, the suspension was exposed to a $110-\mathrm{W}$ highpressure sodium lamp with main emission in the range of 400$800 \mathrm{~nm}$ and air was bubbled at $130 \mathrm{~mL} / \mathrm{min}$ through the solution. The UV light portion of sodium lamp was filtered by $0.5 \mathrm{M} \mathrm{NaNO}_{2}$ solution. All runs were conducted at ambient pressure at $30{ }^{\circ} \mathrm{C}$. At given time intervals, $4 \mathrm{~mL}$ suspension was taken and immediately centrifuged to separate the liquid samples from the solid catalyst. The concentration of methylene blue before and after reaction were measured by means of a UV-visible spectrophotometer at a wavelength of $665 \mathrm{~nm}$. It is the linear relationship between absorbance and concentration of liquid sample in the experimental concentration range. Therefore, the percentage of degradation $\mathrm{D} \%$ was determined by the absorbances of the liquid sample before and after degradation.

\section{RESULTS AND DISCUSSION}

Fig. 1 showed the XRD patterns of carbon-doped $\mathrm{TiO}_{2}$ nanoparticles calcined at temperatures from $300-600{ }^{\circ} \mathrm{C}$. The $\mathrm{X}$-ray diffraction peak at $25.5^{\circ}$ corresponded to characteristic peak of crystal plane (101) of anatase and the peak at $27.6^{\circ}$ corresponded to characteristic peak of crystal plane (110) of rutile in CT-500 and CT-600. The intensities the rutile peaks obviously increased indicating tht the contents of rutile phase increased with the increase of the calcination temperature. No peak assigned to carbon species was observed in prepared $\mathrm{TiO}_{2}$ catalysts.

Fig. 2 showed the UV-visible diffuse reflectance spectra of carbon-doped $\mathrm{TiO}_{2}$ nanoparticles calcined at different temperatures. Obviously, distinct shifts of the absorption bands into the visible light region were observed for carbon doped

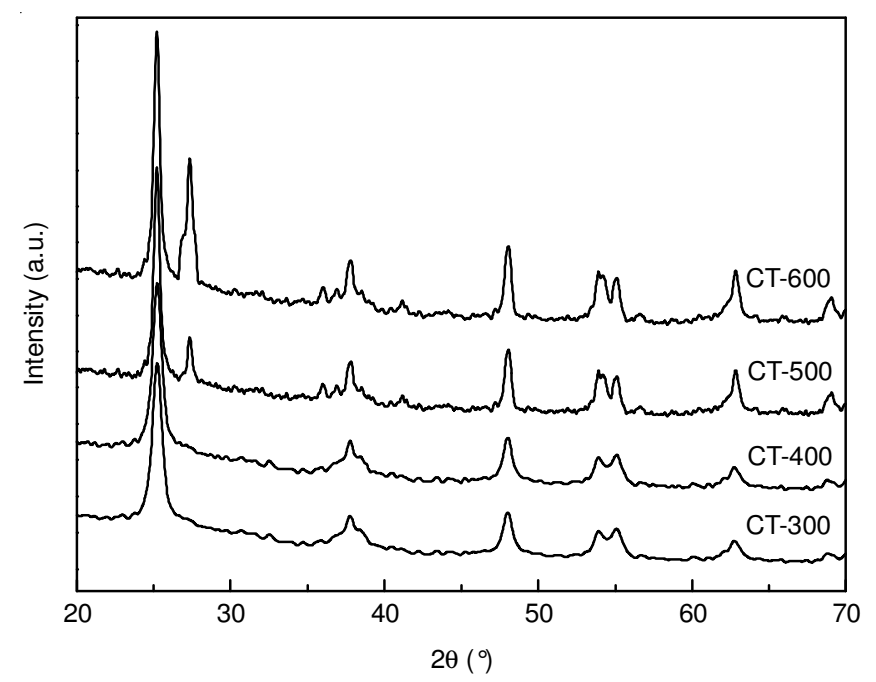

Fig. 1. XRD patterns of carbon doped $\mathrm{TiO}_{2}$ samples

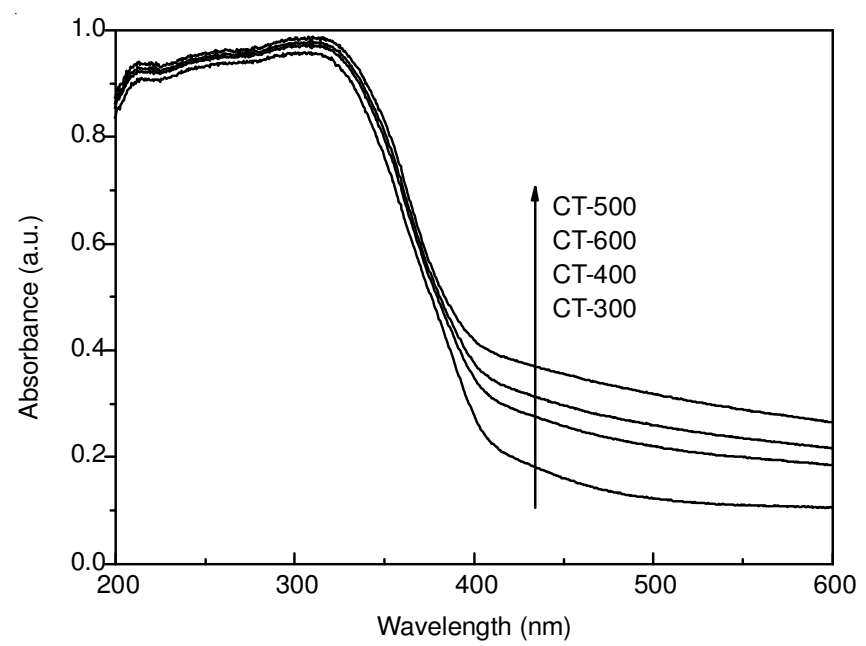

Fig. 2. UV-visible diffuse reflectance spectra of carbon doped $\mathrm{TiO}_{2}$ samples

$\mathrm{TiO}_{2}$ catalysts, which should result from the doping effect. The band gap energies of $\mathrm{TiO}_{2}$ samples were calculated according to the method of Oregan and Gratzel ${ }^{13}$. The results indicated that the band gap of CT-300, CT-400, CT-500 and CT-600 was 2.85, 2.82, 2.80 and $2.85 \mathrm{eV}$, respectively. It is of great importance for its practical application since it could be activated even by sunlight. This showed that the band gap of the carbon-doped $\mathrm{TiO}_{2}$ samples monotonically became narrower with the increase of calcination temperatures and the band gap of carbon-doped $\mathrm{TiO}_{2}$ samples calcined at $500{ }^{\circ} \mathrm{C}$ showed the narrowest among all the carbon doped $\mathrm{TiO}_{2}$ samples. It is known that carbon doping will lead to the formation of $\mathrm{Ti}^{3+}$ species and oxygen vacancy state between the valence and the conduction bands in the carbon-doped $\mathrm{TiO}_{2}$. It is shown that a broad absorption in visible light region ( $>$ $400 \mathrm{~nm}$ ) is observed for all the carbon doped $\mathrm{TiO}_{2}$ samples, accompanied with the changes of color from white to gray. According to report of Ozaki et al ${ }^{14}$, such broad absorption is attributed to the presence of $\mathrm{Ti}^{3+}$ and oxygen vacancies. Therefore, the visible light photocatalytic activity was ascribed to the presence of oxygen vacancy state between the valence band and the conduction band because of the formation of $\mathrm{Ti}^{3+}$ species in the as-synthesized carbon-doped $\mathrm{TiO}_{2}$. 
During the recombination process of photo-induced charge carriers, a certain amount of chemical energy can be released, which would further transform possibly to heat or to light energy. The light energy can be dissipated as radiation, which results in a luminescence emission of semiconductor material, called the photoluminescence phenomenon of the semiconductor. Photoluminescence is a highly sensitive technique used to investigate the photophysical and photochemical properties of solid semiconductors and can provide information on charge separation/recombination of photoinduced charged carriers (electron/hole), as well as surface defects ${ }^{15}$. In general, the lower the photoluminescence intensity, the lower the recombination rate of photo-induced electron-hole pairs, thus the higher the photocatalytic activity. In Fig. 3, obviously, the photoluminescence intensity of carbon doped $\mathrm{TiO}_{2}$ catalysts were lower that that of $\mathrm{P} 25$, indicating the recombination rate of electron-hole pairs were reduced. The photoluminescence intensity decreased from CT-300 to CT-500, whereas increased obviously for CT-600. This is probably due to that the appropriate amount of $\mathrm{Ti}^{3+}$ and oxygen vacancy will trap the photogenerated electrons, thus increase the separation rate, whereas excess $\mathrm{Ti}^{3+}$ and oxygen vacancy will become the recombination center which accelerate the recombination of electron and hole. Thus, in this investigation, the amount of $\mathrm{Ti}^{3+}$ and oxygen vacancy increased with increasing the temperature. The optimal $\mathrm{Ti}^{3+}$ and oxygen vacancy amount was obtained for CT-500, leading to the lowset photoluminescence intensity.

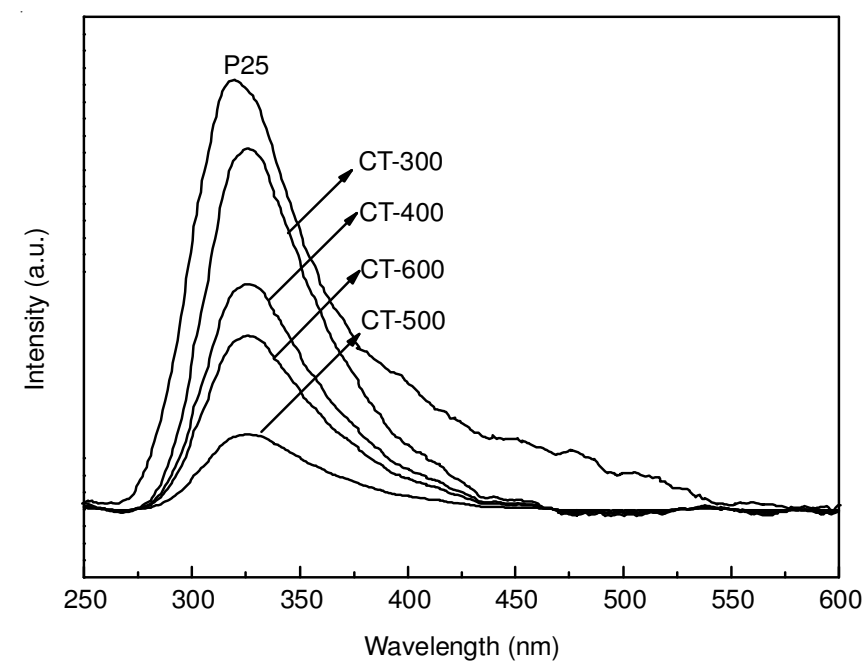

Fig. 3. Photoluminescence spectra of $\mathrm{P} 25$ and carbon doped $\mathrm{TiO}_{2}$ catalysts

XPS is an effective surface test technique for characterizing elemental composition and chemical states. Compared with the spectra of $\mathrm{P} 25$, obvious shifts to lower binding energies were observed for carbon doped $\mathrm{TiO}_{2}$ catalysts in $\mathrm{Ti}$ $2 \mathrm{p}$ region (Fig. $4 \mathrm{a}$ ). It is known that the binding energy of the element is influenced by its electron density. An increase of binding energy implies the lowering of the electron density. Therefore, such lower binding energies are due to the presence of $\mathrm{Ti}$ ion with low valence $\left(\mathrm{Ti}^{3+}\right)$, which exhibit the higher electron density. Besides, with increasing the calcination temperature, the binding energy shift increased, indicating the $\mathrm{Ti}^{3+}$ content increased with increasing the calcination temperature. This is consistent with the UV-visible results.
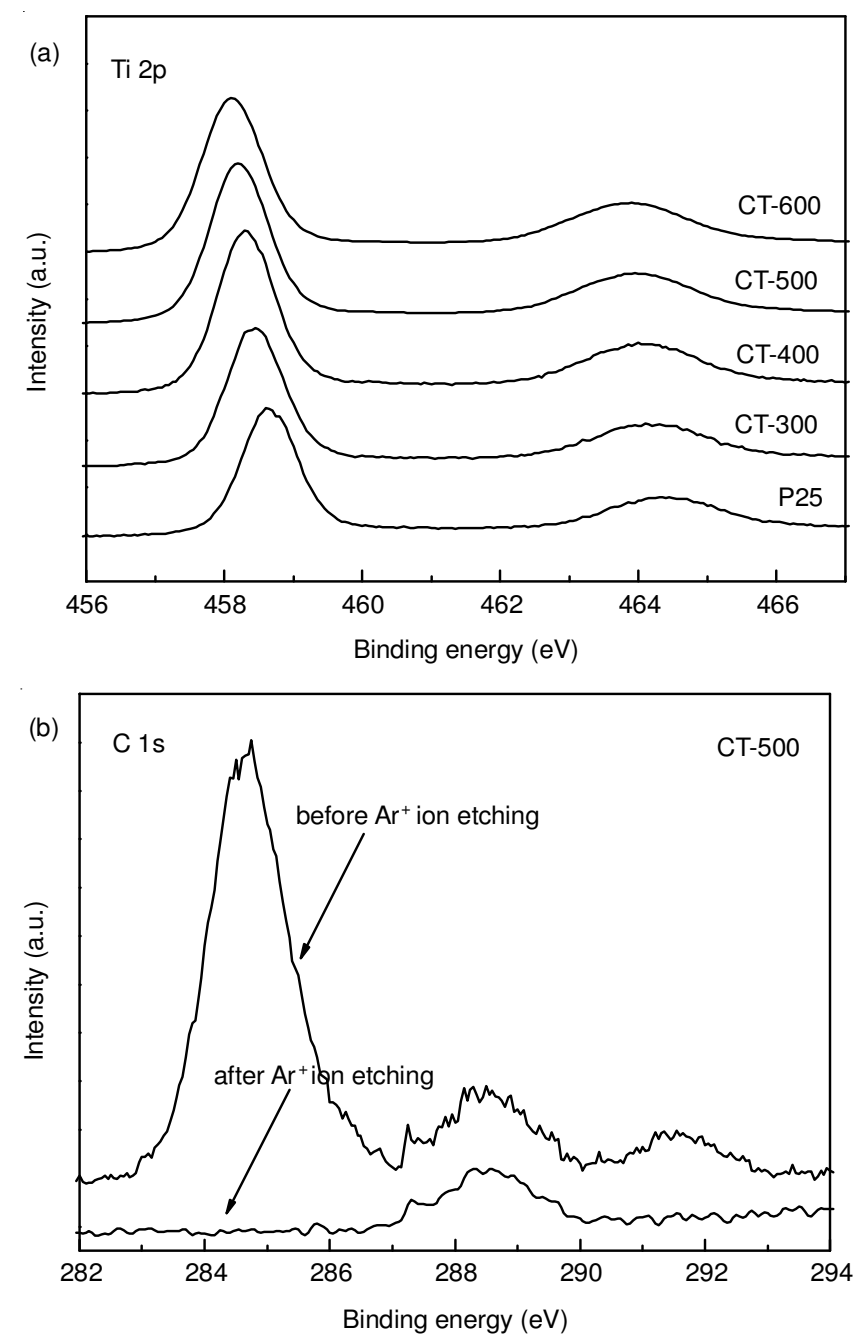

Fig. 4. XP spectra of P25 and prepared catalysts in the region of Ti 2p (a) and $\mathrm{C} 1 \mathrm{~s}(\mathrm{~b})$

The peaks in the $\mathrm{C} 1 \mathrm{~s}$ region (Fig. $4 \mathrm{~b}$ ) were deconvoluted into three contributions. The peak around $284.6 \mathrm{eV}$ was attributed to the C-C group, which is assigned to adventitious elemental carbon. It is reported that carbon can substitute for part of the lattice titanium atoms, forming the Ti-O-C structure whose binding energy is $288.6 \mathrm{eV}^{16}$. It is also possible for carbon to substitute for $\mathrm{O}$ atoms, forming a Ti-C bond whose binding energy is around $282 \mathrm{eV}^{12}$. Therefore, in this investigation, the peak at $288.6 \mathrm{eV}$ was attributed to the carbon doped into $\mathrm{TiO}_{2}$ lattice to form Ti-O-C structure (Fig. 4b). Another peak at higher binding energy $291.5 \mathrm{eV}$ was probably attributed to the electron-deficiency of the $\mathrm{C}$ atom in the $\mathrm{O}-\mathrm{C}=\mathrm{O}$ bond. After $\mathrm{Ar}^{+}$ion etching to get rid of the surface layer, only one peak located at $288.6 \mathrm{eV}$ was observed. This confirmed that carbon atoms were doped into $\mathrm{TiO}_{2}$ lattice, whereas another carbon species only existed as surface carbon film.

Fig. 5 showed the results of photocatalytic decomposition of methylene blue over carbon-doped $\mathrm{TiO}_{2}$. It was found that the photocatalytic activity increased up to $500{ }^{\circ} \mathrm{C}$ and then decreased with increasing calcination temperatures. CT-500 showed the highest photocatalytic activity. The order of activity was totally consistent with that of photoluminescence intensity, which indicated that the high electron-hole separation rate was the key factor for visible light photocatalytic performance. 


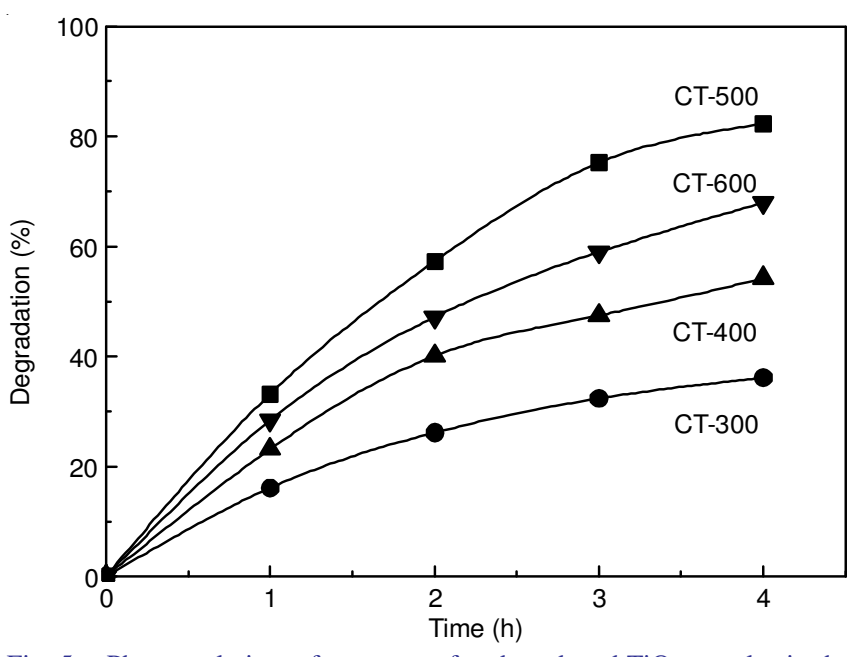

Fig. 5. Photocatalytic performances of carbon doped $\mathrm{TiO}_{2}$ samples in the degradation of methylene blue

Fig. 6 showed the results of the photocatalytic decomposition of methylene blue as a function of the initial concentration of methylene blue. The increased concentration of methylene blue always decreased the photocatalytic efficiency. This could be due to the fact that the carbon-doped $\mathrm{TiO}_{2}$ nanoparticles played an important role in depreciating the effect of the apparent reduction of light penetration into solution with the increase of the concentration of methylene blue.

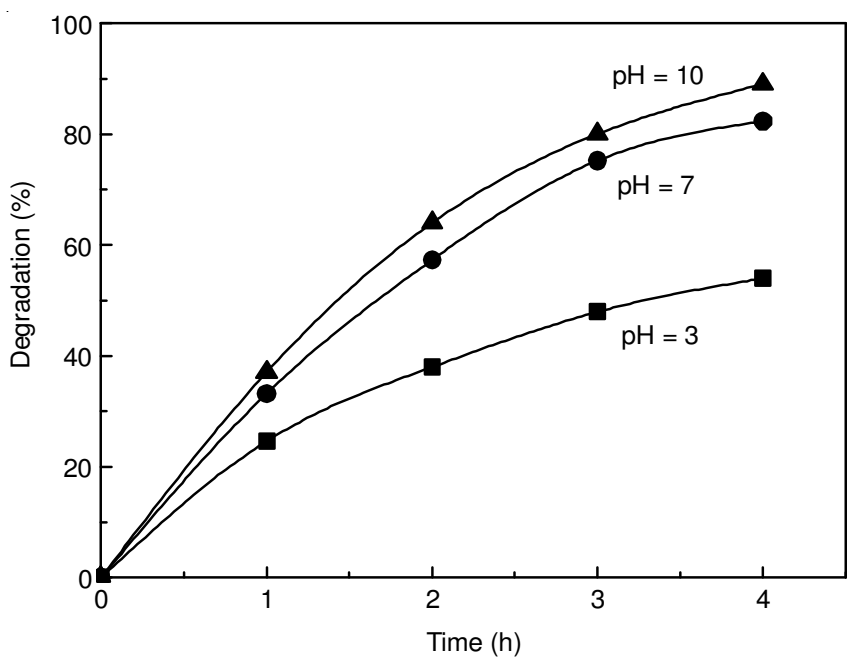

Fig. 6. Effect of $\mathrm{pH}$ value on the degradation of methylene blue with initial concentration of $10 \mathrm{mg} / \mathrm{L}$ over carbon-doped $\mathrm{TiO}_{2}$ nanoparticles calcined at $500{ }^{\circ} \mathrm{C}$

The solution $\mathrm{pH}$ is an important operation parameter of photocatalytic reaction. Park et al. ${ }^{11}$ reviewed a lot of studies and concluded that the interaction of $\mathrm{TiO}_{2}$ with cationic electron donors and electron acceptors would be favored for heterogeneous photocatalytic activity at high $\mathrm{pH}$ greater than the zero point charge of $\mathrm{TiO}_{2}$, while anionic electron donors and electron acceptors would be favored at low $\mathrm{pH}$ less than the zero point charge of $\mathrm{TiO}_{2}$. Therefore, a suitable solution
pH was needed for photocatalytic reactions. Fig. 6 presented the effect of $\mathrm{pH}$ value in the suspension on photocatalytic efficiency. The variation of $\mathrm{pH}$ value showed its strong influence on the methylene blue photodegradation. The photodegradation efficiency as a function of $\mathrm{pH}$ value decreased in the order of $10>7>3$. It was generally accepted that the $\mathrm{pH}$ dependent photodecomposition was mainly ascribed to the variations of surface charge properties of a photocatalyst ${ }^{12}$. Consequently, this changed the adsorption behavior of a dye on catalyst surface. Since methylene blue had a cationic configuration, its adsorption was favored in alkaline solution. The increase of $\mathrm{pH}$ value resulted in a higher adsorption amount of methylene blue on the carbon-doped $\mathrm{TiO}_{2}$ nanoparticles surface. As methylene blue decolorization took place mainly on powder surface, positive holes or hydroxyl radicals might effectively oxidize a suitable amount of methylene blue in close contact with the catalyst.

\section{Conclusion}

Carbon-doped $\mathrm{TiO}_{2}$ nanoparticles was prepared by solgel technique. UV-visible diffuse reflectance spectra showed that carbon-doped $\mathrm{TiO}_{2}$ exhibited obvious absorption in the visible light range, which was ascribed to the presence of oxygen vacancy state between the valence and the conduction bands because of the formation of $\mathrm{Ti}^{3+}$ species in the assynthesized carbon-doped titania. The sample calcined at $500{ }^{\circ} \mathrm{C}$ showed the highest photocatalytic activity under visible light irradiation. In addition, a basic $\mathrm{pH}$ level and a lower initial concentration of methylene blue solution were found to be beneficial for photocatalytic degradation.

\section{REFERENCES}

1. J. Tang, Z. Zou and J. Ye, Chem. Mater., 16, 1644 (2004).

2. R. Asahi, T. Morikawa, T. Ohwaki, A. Aoki and Y. Taga, Science, 293, 269 (2001).

3. S.U.M. Khan, M. Al-shahry and W.B. Ingler Jr., Science, 297, 2243 (2002).

4. T. Umebayashi, T. Yamaki, H. Itoh and K. Asai, Appl. Phys. Lett., 81, 454 (2002).

5. X.T. Hong, Z.P. Wang, W.M. Cai, F. Lu, J. Zhang, Y.Z. Yang, N. Ma and Y.J. Liu, Chem. Mater., 17, 1548 (2005).

6. H. Irie, Y. Watanabe and K. Hashimoto, Chem. Lett., 32, 772 (2003).

7. S. Sakthivel and H. Kisch, Angew. Chem. Int. Ed., 42, 4908 (2003).

8. K. Nagaveni, G. Sivalingam, M.S. Hegde and G. Madras, Appl. Catal. $B, 48,83$ (2004).

9. B. Oregan and M. Gratzel, Nature, 353, 737 (1991).

10. Y.M. Wu, M.Y. Xing and J.L. Zhang, J. Hazard. Mater., 192, 368 (2011).

11. Y. Park, W. Kim, H. Park, T. Tachikawa, T. Majima and W. Choi, Appl. Catal. B, 91, 355 (2009).

12. I. Kang, Q.W. Zhang, S. Yin, T. Sato and F. Saito, Appl. Catal. B: Environ., 80, 81 (2008)

13. B. Oregan and M. Gratzel, Nature, 353, 737 (1991).

14. H. Ozaki, N. Fujimoto, S. Iwamoto and M. Inoue, Appl. Catal. B: Environ., 70, 431 (2007).

15. H. Nakajima, T. Mori, Q. Shen and T. Toyoda, Chem. Phys. Lett., 409, 81 (2005).

16. W.J. Ren, Z.H. Ai, F.L. Jia, L.Z. Zhang, X.X. Fan and Z.G. Zou, Appl. Catal. B, 69, 138 (2007). 